Article

\title{
Drought Characteristic Analysis Based on an Improved PDSI in the Wei River Basin of China
}

\author{
Lei Zou ${ }^{1,2}$, Jun Xia ${ }^{1,2, *}$ and Dunxian She ${ }^{1,2, *}$ \\ 1 State Key Laboratory of Water Resources and Hydropower Engineering Science, Wuhan University, \\ No. 8 Donghu South Road, Wuhan 430072, China; stone_zl@whu.edu.cn \\ 2 Hubei Provincial Collaborative Innovation Center for Water Resources Security, Wuhan 430072, China \\ * Correspondence: xiajun666@whu.edu.cn (J.X.); shedunxian@whu.edu.cn (D.S.); \\ Tel./Fax: +86-27-6877-3772 (J.X. \& D.S.)
}

Academic Editor: Athanasios Loukas

Received: 10 November 2016; Accepted: 27 February 2017; Published: 1 March 2017

\begin{abstract}
In this study, to improve the efficiency of the original Palmer Drought Severity Index (PDSI_original), we coupled the Soil and Water Assessment tool (SWAT) and PDSI_original to construct a drought index called PDSI_SWAT. The constructed PDSI_SWAT is applied in the Wei River Basin (WRB) of China during 1960-2012. The comparison of the PDSI_SWAT with four other commonly used drought indices reveals the effectiveness of the PDSI_SWAT in describing the drought propagation processes in WRB. The whole WRB exhibits a dry trend, with more significant trends in the northern, southeastern and western WRB than the remaining regions. Furthermore, the drought frequencies show that drought seems to occur more likely in the northern part than the southern part of WRB. The principle component analysis method based on the PDSI_SWAT reveals that the whole basin can be further divided into three distinct sub-regions with different drought variability, i.e., the northern, southeastern and western part. Additionally, these three sub-regions are also consistent with the spatial pattern of drought shown by the drought frequency. The wavelet transform analysis method indicates that the El Niño-Southern Oscillation (ENSO) events have strong impacts on inducing droughts in the WRB. The results of this study could be beneficial for a scientific water resources management and drought assessment in the current study area and also provide a valuable reference for other areas with similar climatic characteristics.
\end{abstract}

Keywords: drought variability; SWAT model; principal component analysis; wavelet transform; Wei River Basin

\section{Introduction}

Drought is one of the most destructive natural hazards which has huge effects on regional agriculture, economics, water resources and environment [1-3]. Droughts occurred more frequently due to global climate change and rapid socio-economic development during the past several decades [2,4]. Generally, drought can be considered as a period of water deficit or a negative water imbalance caused by water supply deficiency with a sustained lack of precipitation or excess evapotranspiration during an extended period [5,6]. To date, a variety of drought indices have been proposed or developed $[7,8]$ to promote the adequate estimation of regional drought characteristics in drought monitoring and prediction, which is of critical importance for decision making, drought risk assessment and potential impacts mitigation [9]. These indices can be broadly categorized into four types, i.e., meteorological, agricultural, hydrological and socioeconomic drought [10].

One of the most common indices used to analyze drought hazards is the Palmer Drought Severity Index (noted as PDSI_original), which was firstly proposed by Palmer [11]. The PDSI_original is considered to be a landmark for drought characterization due to its wide application in the 
drought analysis by extensive users covering meteorologists, hydrologists and also many government agencies [7,12]. The PDSI_original could be used to detect the severity of a dry or wet conditions (the greater the absolute value of the index, the more severe the dry or wet conditions). It is derived from the Palmer's drought model using a two-layer bucket model involving precipitation, evapotranspiration, runoff and soil moisture. However, the major drawback of the PDSI_original is mainly referred to the simple hydrological two-layer bucket model used without considering the effects of factors such as land cover, topography and spatial heterogeneity on the complex hydrological process, which may reduce its efficiency in the accurate drought description. Some attempts have already been undertaken to improve the PDSI_original. For example, Wells et al. [13] adopted an automatically calculating procedure to develop the self-calibrated PDSI (SC-PDSI), which had improved the spatial comparability of PDSI among diverse climatological regions. Mavromatis et al. [14] tried to modify scheme of evapotranspiration (PET) algorithms with Priestley-Taylor's approach in original PDSI. However, based on the effects of PET algorithms, more works are still needed for the hydrological accounting in calculating PDSI_original. An efficient way to overcome these shortcomings in the computation of PDSI is to replace the simple two-layer bucket model with distributed hydrological models that can provide more accurate simulation of the hydrological processes. Yan et al. [15] used the Soil and Water Assessment Tool (SWAT) and Ma et al. [16] employed the Variable Infiltration Capacity (VIC) model to substitute the simple two-layer bucket model in the PDSI computation. However, the parameters (such as the characteristic coefficient K) in the PDSI computation they used was not changed and the same as the PDSI_original. Provided that the variables are changed, a new adjustment should be taken to ensure the reasonable of the new calculation.

Assessing the spatiotemporal characteristics of drought is of great interest given that droughts may have great variability in space and time. Multivariate analysis and geostatistical methods are commonly used in the regional analysis of droughts. Some of common approaches for the regionalization of drought characteristics include the region of influence approach [17], the entropy approach [18], the method of residuals method [19] and the principal component analysis (PCA) approach [20]. In recent years, the PCA method [20] has attracted more and more interests in numerous studies to analyze the temporal and spatial drought variability as it can effectively retain the characteristics of datasets through a lower dimension with a simplified structure [21-23]. For example, Martins et al. [21] studied the spatial variability of drought in Portugal with the PCA method by reducing the dimension and extracting the structural information on a large number of different drought indices time series; Gocic and Trajkovic [22] used the PCA method to capture the temporal and spatial patterns of drought in Serbia by reducing dimensionality in a group of SPI time series; Liu et al. [23] identified the representative locations and sub-regions with the PCA method considering the drought characteristics to provide a further regional view of drought conditions across the Loess Plateau in China. In conclusion, the characterization of the temporal variability of drought which can be represented by the PC scores deriving from the PCA is very useful for the adequate water resources planning and management.

In this study, we intend to analyze the spatiotemporal characteristics of drought by comparing various drought indices in the Wei River Basin (WRB), which is located in the Loess Plateau in the northwest of China. The WRB is a main grain-yielding and an important industrial and commercial area in China, however, this region is always affected by severe drought hazards since the historic times [24]. Thus, it is important to investigate the spatiotemporal characteristics of droughts in this area so as to ensure the security of agriculture production and the socioeconomic development. However, few comprehensive research has been undertaken on spatiotemporal variability of drought using the PCA and drought indices in the WRB at basin scale. Furthermore, to overcome the disadvantages of PDSI_original in the sufficient simulation of multiple variables, such as precipitation, evapotranspiration, runoff and soil moisture, we attempts to use the distributed model (SWAT model in this study) to substitute the simple two-layer structure in the original PDSI. That is to say, we expect to improve the efficiency of PDSI by coupling the SWAT model (noted as PDSI_SWAT) to 
replace the variables used in the PDSI's computation. In addition, to detect the performances of PDSI_original and PDSI_SWAT, three commonly used drought indices (i.e., Standardized Precipitation Index (SPI, Mckee et al. [25]), Standardized Soil Moisture Index (SSI, Hao et al. [26]) and Standardized Precipitation Evapotranspiration Index (SPEI, Vicente-Serrano et al. [27])), reflecting dry/wet conditions of atmosphere and basin storage respectively, were selected for comparison. Besides, the PCA method will be performed to identify the sub-regions with independent drought characteristics of the WRB, which will help further find out the temporal patterns of the droughts in various regions and therefore practically facilitate the regional water resources management. El Niño-Southern Oscillation (ENSO) is a typical atmosphere-ocean phenomenon in the tropical Pacific and also one of the most important factors influencing world climate [28,29]. When an ENSO event occurs, the atmospheric-oceanic anomaly in the tropical Pacific can affect the patterns of various climate parameters such as precipitation and temperature worldwide [30]. Given the impact of ENSO events on the climate variability in China, we will also investigate the possible linkage between ENSO and drought variations in different sub-regions obtained by PCA in our study area.

The main objectives of the present study are to: (1) improve the traditional PDSI by coupling the SWAT model (PDSI_SWAT) to better represent the spatial heterogeneity of regional drought; (2) find out the most suitable drought index that can describing the drought conditions in the WRB; (3) identify sub-regions using the PCA method and generate the principle components of drought in various regions in the WRB for regional drought monitoring and predictions; (4) investigate the multi-scale relations between ENSO and drought variations in different sub-regions.

\section{Study Area and Data}

\subsection{Study Area}

The Wei River $\left(33^{\circ} 40^{\prime}-37^{\circ} 26^{\prime} \mathrm{N}, 103^{\circ} 57^{\prime}-110^{\circ} 27^{\prime} \mathrm{E}\right.$; Figure 1a) is located in the northwest of China, originating from the Niaoshu Mountain in the Weiyuan country of Gansu province and running into Yellow River at Tongguan. It is the largest tributary of the Yellow River and covers a drainage area of $134,800 \mathrm{~km}^{2}$. There are two large tributaries in the WRB, the Jing River and the Beiluo River, which are located in the middle and lower reaches of the basin, respectively. The WRB's climate is characterized by semi-arid and semi-humid continental monsoon with an average annual precipitation of about $545 \mathrm{~mm}$. The mean annual temperature in the WRB is between 7.8 and $13.5^{\circ} \mathrm{C}$. The land pan evaporation is approximately $500 \mathrm{~mm}$ and the annual potential evapotranspiration ranges from 660 to $1600 \mathrm{~mm}$. The WRB is a grain-yielding and important economic area in northwestern China, especially after the foundation of Guanzhong-Tianshui Economic Zone [31].

Drought hazards with long duration and high severity occur frequently in the WRB and have caused huge losses of grain production and socio-economic fabric in recent years. According to Guo and Zha [32], 255 drought events have occurred in the Jing River Bain during the past 510 years (1470-1979) with 103 of them being severe or extreme. During 1949-1995, the WRB has encountered 32 drought events, which affected more than $20 \%$ of the entire basin and restricted the sustainable development of agriculture [24].

\subsection{Data Description}

In this study, the 3 arc-second (90 m) digital elevation model (DEM) downloaded from the Shuttle Radar Topography Mission (SRTM) Digital Elevation Database of USGS/NASA is used. Soil type and land use data at a $1 \mathrm{~km}$ resolution were obtained from the Data Center Resources and Environment Sciences, Chinese Academy of Sciences (RESDC, http:/ / www.resdc.cn). The associated soil database contains detailed information about physical soil attributes of different soil horizons.

Daily observed meteorological data collected from 28 meteorological stations (Figure 1a and Table 1) in the WRB and its surrounding area were used as the input data for the SWAT model. The meteorological data, including precipitation, air temperature (maximum, minimum and mean 
temperature), relative humidity, sunshine hour and wind speed, were provided by the National Climate Center of the China Meteorological Administration (CMA) (http:/ / cdc.cma.gov.cn). Observed monthly streamflow at four hydrological stations (Linjiacun, Zhangjiashan, Xianyang and Huaxian) from 1960 to 2012 and monthly irrigation data from 1990-2012 were provided by the Hydrology Bureau of the Yellow River Conservancy Commission. The irrigation data were allocated into each sub-basin according to its areal proportion. In addition, a 10-day 50-cm soil moisture dataset [33] at 32 China Agrometeorological stations (Figure 1a and Table 1) in the study area were also collected to verify the simulation of soil moisture by the SWAT model. Measurements were taken on 8th, 18th, and 28th days of each month, at depth of 10, 20,30,50,70, and $100 \mathrm{~cm}$. The 10-day dataset was averaged into monthly and yearly for the comparison between the simulated and observed soil moisture. The soil moisture dataset is given as the relative soil moisture, which is computed as $R=\theta / \theta_{f} \times 100 \%$, where $\theta_{f}$ and $\theta$ is the volumetric soil water content at field capacity and the volumetric soil water content, respectively.
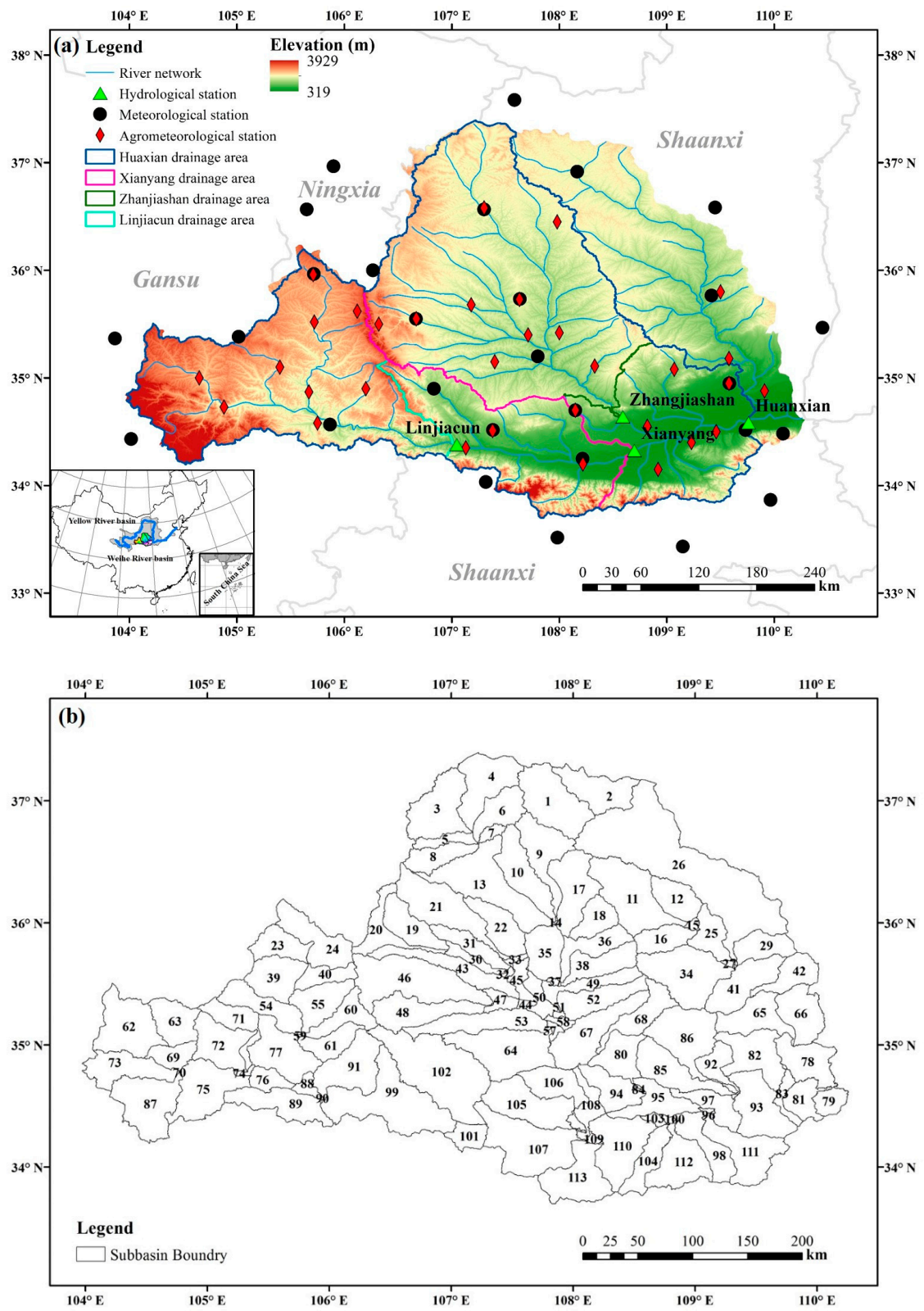

Figure 1. (a) Location, topography, river systems and distribution of stations in the Wei River Basin (WRB); (b) The sub-basin delineation of the WRB. 
Table 1. Basic information of the stations.

\begin{tabular}{|c|c|c|c|c|c|c|c|c|c|c|c|}
\hline Station & Name & Longitude & Latitude & Province & Sub-Basin & Station & Name & Longitude & Latitude & Province & Sub-Basin \\
\hline \multirow{4}{*}{$\begin{array}{l}\text { Hydrological } \\
\text { Station }\end{array}$} & Linjiacun & 107.05 & 34.38 & Shaanxi & 99 & \multirow{32}{*}{$\begin{array}{l}\text { Agrometeorological } \\
\text { station }\end{array}$} & Huanxian & 107.30 & 36.58 & Gansu & 13 \\
\hline & Zhangjiashan & 108.59 & 34.64 & Shaanxi & 80 & & $\mathrm{X}_{\mathrm{iji}}$ & 105.71 & 35.96 & Ningxia & 24 \\
\hline & Xianyang & 108.70 & 34.32 & Shaanxi & 110 & & Jingning & 105.72 & 35.52 & Gansu & 39 \\
\hline & Huaxian & 109.76 & 34.58 & Shaanxi & 83 & & Tongwei & 105.40 & 35.10 & Gansu & 72 \\
\hline \multirow{28}{*}{$\begin{array}{l}\text { Meteorological } \\
\text { station }\end{array}$} & Linyao & 103.87 & 35.37 & Gansu & - & & Longde & 106.12 & 35.62 & Ningxia & 40 \\
\hline & Huajialing & 105.02 & 35.38 & Gansu & - & & Pingliang & 106.67 & 35.55 & Gansu & 46 \\
\hline & Dingbian & 107.58 & 37.58 & Shaanxi & - & & Jingyuan & 106.32 & 35.50 & Ningxia & 46 \\
\hline & Wuqi & 108.17 & 36.92 & Shaanxi & 2 & & Xifengzhen & 107.63 & 35.73 & Gansu & 35 \\
\hline & Haiyuan & 105.65 & 36.57 & Ningxia & - & & Lingtai & 107.40 & 35.15 & Gansu & 53 \\
\hline & Tongxin & 105.90 & 36.97 & Ningxia & - & & Zhenyuan & 107.18 & 35.68 & Gansu & 30 \\
\hline & Guyuan & 106.27 & 36.00 & Ningxia & - & & Jingchuan & 107.71 & 35.40 & Gansu & 50 \\
\hline & Huanxian & 107.30 & 36.57 & Gansu & 13 & & Huachi & 107.98 & 36.45 & Gansu & 17 \\
\hline & Yan'an & 109.45 & 36.58 & Shaanxi & - & & Ningxian & 108.00 & 35.42 & Gansu & 52 \\
\hline & $\mathrm{X}_{\mathrm{iji}}$ & 105.72 & 35.97 & Ningxia & 24 & & Xunyi & 108.33 & 35.11 & Shaanxi & 80 \\
\hline & Pingliang & 106.67 & 35.55 & Gansu & 46 & & Baishui & 109.58 & 35.18 & Shaanxi & 65 \\
\hline & Xifengzhen & 107.63 & 35.73 & Gansu & 35 & & Luochuan & 109.50 & 35.80 & Shaanxi & 29 \\
\hline & Changwu & 107.80 & 35.20 & Shaanxi & 58 & & Tongchuan & 109.07 & 35.08 & Shaanxi & 86 \\
\hline & Luochuan & 109.42 & 35.77 & Shaanxi & 29 & & Pucheng & 109.58 & 34.95 & Shaanxi & 82 \\
\hline & Pucheng & 109.58 & 34.95 & Shaanxi & 82 & & Longxi $^{\circ}$ & 104.65 & 35.00 & Gansu & 62 \\
\hline & Hancheng & 110.45 & 35.47 & Shaanxi & - & & Qin'an & 105.67 & 34.87 & Gansu & 77 \\
\hline & Minxian & 104.02 & 34.43 & Gansu & - & & Wushan & 104.88 & 34.73 & Gansu & 75 \\
\hline & Longxian & 106.83 & 34.90 & Shaanxi & 102 & & Tianshui & 105.75 & 34.58 & Gansu & 89 \\
\hline & Tianshuibeidaoqu & 105.87 & 34.57 & Gansu & 89 & & Zhangjiachuan & 106.20 & 34.90 & Gansu & 91 \\
\hline & Fengxiang & 107.38 & 34.52 & Shaanxi & 105 & & Baoji & 107.13 & 34.35 & Shaanxi & 101 \\
\hline & Taibai & 107.32 & 34.03 & Shaanxi & - & & Fengxiang & 107.38 & 34.51 & Shaanxi & 105 \\
\hline & Yongshou & 108.15 & 34.70 & Shaanxi & 94 & & Yongshou & 108.15 & 34.70 & Shaanxi & 94 \\
\hline & Wugong & 108.22 & 34.25 & Shaanxi & 110 & & Jingyang & 108.82 & 34.55 & Shaanxi & 95 \\
\hline & Huashan & 110.08 & 34.48 & Shaanxi & 79 & & Wugong & 108.22 & 34.20 & Shaanxi & 109 \\
\hline & Huaxian & 109.73 & 34.52 & Shaanxi & 81 & & Chang'anxian & 108.92 & 34.15 & Shaanxi & 112 \\
\hline & Foping & 107.98 & 33.52 & Shaanxi & - & & Dali & 109.91 & 34.88 & Shaanxi & 78 \\
\hline & Shangzhou & 109.97 & 33.87 & Shaanxi & - & & Lintong & 109.23 & 34.40 & Shaanxi & 97 \\
\hline & Zhen'an & 109.15 & 33.43 & Shaanxi & - & & Weinan & 109.46 & 34.50 & Shaanxi & 93 \\
\hline
\end{tabular}


As a widely used index of ENSO activity, the Niño 3.4 SST index covering 1961-2012 was used to investigate the potential connection between ENSO and the drought variations. The data were obtained from the Climate Prediction Centre (CPC) (http:/ / www.cpc.ncep.noaa.gov).

\section{Methodology}

\subsection{Definitions of Drought Indices}

\subsubsection{SPI, SPEI and SSI}

The calculation procedure of SPI for any location is based on long-term precipitation data accumulated over different time scales (e.g., 1-month, 3-month, 6-month, 12-month). The precipitation data series are firstly fitted into a proper probability distribution, usually a Gamma distribution, which is then transformed into a normal distribution by the inverse normal function [34]. The details of the computation procedures can be found in Mckee et al. [25]. SSI is an index of agricultural droughts, which is developed based on the concept of SPI, and it also facilitates the comparison of different locations across the study area with other indices for drought evaluation. The calculation of SSI is the same as SPI by replacing the precipitation series with soil moisture series. The SPEI calculation is also based on the original SPI calculation procedures. The computation of SPEI is similar to SPI by replacing the precipitation with the difference between precipitation and potential evapotranspiration. The detailed processes of the SPEI can be found in Vicente-Serrano et al. [27].

The dry and wet conditions can be classified into nine classes based on the SPI/SPEI/SSI values (see Table 2).

Table 2. The dry and wet classifications based on the Standardized Precipitation Index (SPI)/Standardized Precipitation Evapotranspiration Index (SPEI)/Standardized Soil Moisture Index (SSI).

\begin{tabular}{cccc}
\hline Categories & SPI/SPEI/SSI Values & Categories & SPI/SPEI/SSI Values \\
\hline Extreme Drought & $(-\infty,-2]$ & Slight Wet & {$[0.5,1)$} \\
Severe Drought & $(-2,-1.5]$ & Moderate Wet & {$[1,1.5)$} \\
Moderate Drought & $(-1.5,-1]$ & Severe Wet & {$[1.5,2)$} \\
Slight Drought & $(-1,-0.5]$ & Extreme Wet & {$[2,+\infty)$} \\
Normal & $(-0.5,0.5)$ & & \\
\hline
\end{tabular}

\subsubsection{A Brief Description of PDSI_original}

The PDSI is a comprehensive hydro-meteorological drought index, which can be used to represent relative dryness conditions. The following brief description is based on the original study of Palmer [11], which describes how to calculate the PDSI at 1-month time steps. In the hydrologic accounting, eight hydrological variables including evapotranspiration (ET), recharges to soils (R), runoff (RO), water loss to the soil layers (L), and their potential values (PET; PR; PRO; PL) were calculated by the two-lay model. The climatically appropriate for existing conditions precipitation $(\hat{P})$ and four water-balance coefficients $\alpha_{i}, \beta_{i}, \gamma_{i}, \delta_{i}$ are computed as follows for each month $i$ :

$$
\begin{gathered}
\hat{P}=\alpha_{i} P E T+\beta_{i} P R+\gamma_{i} P R O-\delta_{i} P L \\
\alpha_{i}=\frac{\overline{E T_{i}}}{\overline{P E T_{i}}}, \quad \beta_{i}=\frac{\overline{R_{i}}}{\overline{P R_{i}}}, \quad \gamma_{i}=\frac{\overline{R O_{i}}}{\overline{P R O_{i}}}, \quad \delta_{i}=\frac{\overline{L_{i}}}{\overline{P L_{i}}}
\end{gathered}
$$

The output of hydrologic accounting is the moisture departure $\left(d_{i}\right)$, estimated as the difference between actual precipitation and the computed $\hat{P}$ in a given month $i$ :

$$
d_{i}=P-\hat{P}
$$


Then, in order to modify $d$ series, Palmer [11] multiplied $d$ by a climatic characteristic coefficient $K$ to derive the moisture anomaly index or the $\mathrm{Z}$ index $(\mathrm{Z}=K \times d)$. More details about the modification can be found in Palmer [11].

\subsubsection{Coupling PDSI with the SWAT Model (PDSI_SWAT)}

SWAT model is a semi-distributed and continuous time step basin scale conceptual model, which is extensively applied to predict the impacts of various management practices on water, sediment, and agriculture chemical yields to watersheds of different scales and characteristics $[35,36]$. The SWAT model partitions the entire watershed into sub-basins based on the topography, and then further divides each sub-basin into hydrologic response units (HRU) based on the soil and land cover characteristics. In this study, the WRB is divided into 113 sub-basins (Figure 1b), which satisfactorily represent the watershed's heterogeneity. SUFI-2 (Sequential Uncertainty Fitting, ver. 2) [37] was used for a combined calibration and uncertainty analysis, linked to SWAT in the calibration package SWAT-CUP.

In this study, we use the outputs from the SWAT model to replace the corresponding variables in the computation of PDSI. The eight hydrological variables previously derived from the two-layer model were replaced by the output variables from the SWAT model simulations. Data series of PET, ET and RO can be directly obtained from SWAT simulation, and other five variables can be estimated as follows:

$$
\begin{gathered}
R_{i}=\max \left(0,\left(S W_{i}-S W_{0}\right)\right) \\
L_{i}=\max \left(0,\left(S W_{0}-S W_{i}\right)\right) \\
P R O_{i}=A W C-P R_{i}=S W_{0} \\
P R_{i}=A W C-S W_{0} \\
P L_{i}=\min \left(P E T_{i}, S W_{0}\right)
\end{gathered}
$$

where $S W_{i}$ is the soil water content of month $i$ and $S W_{0}$ is the initial soil water content at the beginning month $i$. Both of them are derived from the outputs of SWAT model. AWC is available soil moisture capacity and is determined from the established SWAT soil database which computed by the SPAW software based on the soil attributes. There eight SWAT derived variables are further used to replace the corresponding variables in Equations (1)-(3) to accomplish hydrologic accounting calculations. Then, a modified $K$ can be derived for each basin and PDSI_SWAT can be computed as:

$$
\begin{gathered}
K=\frac{216.32}{\sum_{i=1}^{12} D K^{\prime}} K^{\prime} \\
K^{\prime}=1.8320 \lg \left(\frac{\overline{P E T}+\bar{R}+\overline{R O}}{(\bar{P}+\bar{L}) / \bar{D}}\right)+5.9561 \\
\text { PDSI_SWAT } T_{i}=\frac{Z_{i}}{56.237}+0.715 P D S I_{-} S W A T_{i-1}
\end{gathered}
$$

where $D$ is the monthly mean of the absolute value of $d$. Table 3 shows the classification of dry and wet conditions of PDSI_SWAT. 
Table 3. The dry and wet classifications based on the Palmer Drought Severity Index coupled with the Soil and Water Assessment tool (PDSI_SWAT).

\begin{tabular}{cccc}
\hline Categories & PDSI_SWAT Values & Categories & SPI/SSI Values \\
\hline Extreme Drought & $(-\infty,-4]$ & Slight Wet & {$[1,2)$} \\
Severe Drought & $(-4,-3]$ & Moderate Wet & {$[2,3)$} \\
Moderate Drought & $(-3,-2]$ & Severe Wet & {$[3,4)$} \\
Slight Drought & $(-2,-1]$ & Extreme Wet & {$[4,+\infty)$} \\
Normal & $(-1,1)$ & & \\
\hline
\end{tabular}

\subsection{Simple Linear Regression Test Method}

The linear regression test method [38] is selected to detect the trend of drought in this study. It is a parametric test that assumes the data is normally distributed, and tests for linear trend by examining the relationship between the time and the variable of interest. The test statistic $S$ follows a Student distribution with $n-2$ degrees of freedom under the null hypothesis, which is estimated by:

$$
S=\hat{b} / \hat{\sigma}
$$

where $\hat{b}$ and $\hat{\sigma}$ is the regression gradient and standard error, respectively. The application of this test assumes that the errors are independent and follow the same normal distribution with 0 mean. The background theory and detailed methodology can be referred to Kundzewicz and Mondiale [38].

\subsection{Principal Componrnt Analysis}

Principal Component Analysis (PCA) is a multivariate technique that reduces dimensionality and extracts structural information in a dataset, which is widely used in hydrology, environmental sciences and drought regionalization [39,40]. It is based on the estimation of the eigenvalues and eigenvectors from the characteristic equation. Richman [41] defined six modes of PCA due to different combination of time, objects and attributes. In this study, the S-mode (data matrix with rows for the drought index and columns for the sub-basins) with the varimax orthogonal rotation method [42] was applied on the PDSI_SWAT time series to identify the spatial patterns of drought. The spatial patterns (eigenvectors) defined in this way are called loadings in our study. The loadings represent the correlation between the original data and the corresponding principal component time series for each sub-basin and the PC scores are computed according to the covariance matrix of the index data (e.g., SPI3 in this study) with the corresponding eigenvalues and eigenvectors. The results of PCA were used to identify the representative sub-regions with different types of drought characteristics.

The rule of thumb (North et al. [43]) and scree plot of eigenvalues were used to make the decision on how many principal components to retain for rotation. The Kaiser-Meyer-Olkin (KMO) test [44] and Bartlett's test of sphericity [45] are applied to test the quality of the principal components of the PDSI_SWAT time series before the application of the PCA method.

\subsection{Wavelet Transform Analysis Method}

To evaluate the possible impacts of ENSO on droughts in the distinct regions obtained by PCA, the wavelet transform approach including cross-wavelet power and wavelet coherence, was used to detect the relationship between the RPC series and the Niño 3.4 SST Index in our study. This method can identify the localized correlation coefficients and their phase relationship between two time series [46]. A brief introduction of the cross wavelet method (XWT) and the wavelet coherence (WTC) are provided below, with more detailed information available from Torrence and Compo [47].

For the two time series $X_{t}$ and $Y_{t}$, the cross wavelet spectrum is defined as follows:

$$
W_{t}^{X Y}(s)=W_{t}^{X}(s) W_{t}^{Y *}(s)
$$


where $W_{t}^{X}(s)$ denotes the wavelet transform of time series $X$ at frequency scale $s$, and $W_{n}^{Y *}(s)$ represents the complex conjugate of wavelet transform $W_{n}^{Y}(s)$ for time series $Y$. In addition, to overcome the issue that the XWT could produce misleading results while the spectrum of one of the time series exhibits strong peaks [48], the WTC was also used in our study. For the wavelet coherence, the cross wavelet power is normalized by the spectrum of the two time series. An ideal wavelet coherence could be defined as:

$$
R_{t}(s)=\frac{\left|S\left(s^{-1} W_{t}^{X Y}(s)\right)\right|}{\sqrt{s\left(s^{-1}\left|W_{t}^{X}(s)\right|^{2}\right)} \sqrt{s\left(s^{-1}\left|W_{t}^{Y}(s)\right|^{2}\right)}}
$$

where $S$ is a smoothing operator.

\subsection{Evaluation Metrics}

Three hydrological model performance indices, i.e., the Nash-Sutcliffe efficiency coefficient with logarithmic values ( $\mathrm{NSE}_{\text {In }}$ ), coefficient of determination $\left(R^{2}\right)$ and proportion of explained variance (PEV), are selected to evaluate the efficiency of the SWAT model. The NSE In and $R^{2}$ values tending to 1 and the PEV tending to $100 \%$ indicated the model simulation is better and more reliable.

$$
\begin{gathered}
\mathrm{NSE}_{\mathrm{In}}=1-\frac{\sum_{i=1}^{n}\left(\operatorname{In} Q_{o b s, i}-\operatorname{In} Q_{\text {sim }, i}\right)^{2}}{\sum_{i=1}^{n}\left(\operatorname{In} Q_{o b s, i}-\operatorname{In} \overline{Q_{o b s}}\right)^{2}} \\
R^{2}=\left(\frac{\sum_{i=1}^{n}\left(Q_{o b s, i}-\overline{Q_{o b s, i}}\right)\left(Q_{s i m, i}-\overline{Q_{s i m}}\right)}{\sqrt{\sum_{i=1}^{n}\left(Q_{o b s, i}-\overline{Q_{o b s}}\right)^{2} \sum_{i=1}^{n}\left(Q_{s i m, i}-\overline{Q_{s i m}}\right)^{2}}}\right)^{2} \\
\operatorname{PEV}=\left(1-\frac{\operatorname{Var}\left(Q_{s i m}-Q_{o b s}\right)}{\operatorname{Var}\left(Q_{o b s}\right)}\right) \times 100 \%
\end{gathered}
$$

where $Q_{o b s, i}$ and $Q_{s i m, i}$ are the observed and simulated monthly streamflow, respectively.

\section{Results}

\subsection{Implementation of the SWAT Model into the PDSI}

\subsubsection{Model Calibration and Validation}

In this study, the whole time period is divided into two parts: calibration period from 1960 to 1996 and validation period from 1997 to 2012. Figure 2 shows the comparison between the observed and simulated monthly streamflow during the calibration and validation periods in the four hydrological stations. We can find that the SWAT model performs well not only in the calibration period but also in the validation period at all stations. The performance of the SWAT model in the WRB is satisfactory and acceptable since the $\mathrm{NSE}_{\text {In }}$ values range from 0.71 to 0.88 , the $R^{2}$ values vary from 0.73 to 0.89 and the PEV values range from $80 \%$ to $92 \%$. Moreover, more than $90 \%$ of the observed streamflow are located in the band of the $95 \%$ confidence intervals of the simulated streamflow, which also indicates that the SWAT model can give robust estimates of the monthly water balance during both the calibration and validation periods. 


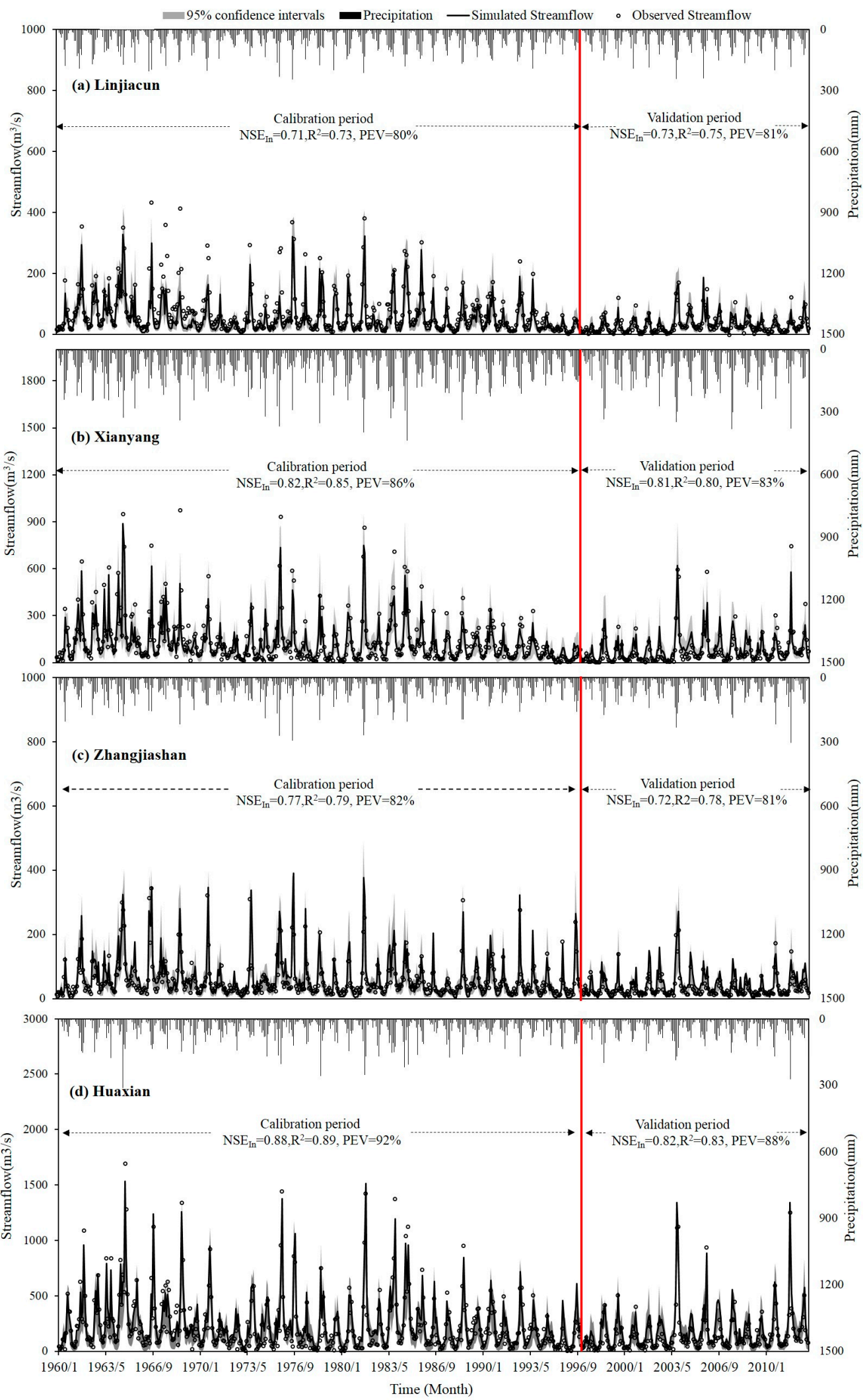

Figure 2. Comparison between the observed and simulated monthly streamflow for the four hydrological stations in WRB during the calibration and validation periods: (a) Linjiacun; (b) Xianyang; (c) Zhangjiashan and (d) Huaxian. The gray depicts the $95 \%$ confidence intervals of simulated monthly streamflow. 
Furthermore, the simulation efficiency of the SWAT model for the soil moisture is also tested here as it is a key state variable in the hydrologic cycle and is often used to compute the drought indices representing agricultural drought. In order to validate the simulated soil moisture $\left(\mathrm{mmH}_{2} \mathrm{O}\right)$ by SWAT model with the observed relative soil moisture under the unified dimension, we convert the observed relative soil moisture and simulated moisture into volumetric soil water content. Figure 3a shows the simulated and observed soil moisture in the 32 agrometeorological stations (Figure 1). The linear correlation coefficient $(R=0.63)$ indicates a good consistency between the observed and simulated soil water content. In addition, we also provide the variations of the standardized soil moisture content of observed and simulated values to further test the efficiency of SWAT model (Figure 3b). Such comparison can avoid the error of conversion and obtain the reasonable evaluation on the variation trend. We can observe a similar pattern of interannual variability between the observed and simulated values with a high linear correlation coefficient $(R=0.752)$, which also demonstrates the good efficiency of SWAT model in the simulation of soil moisture.

To sum up, we can obtain the output variables through the SWAT model, including precipitation, potential evapotranspiration, runoff, and soil moisture in the 113 sub-basins, to compute various drought indices in the WRB.

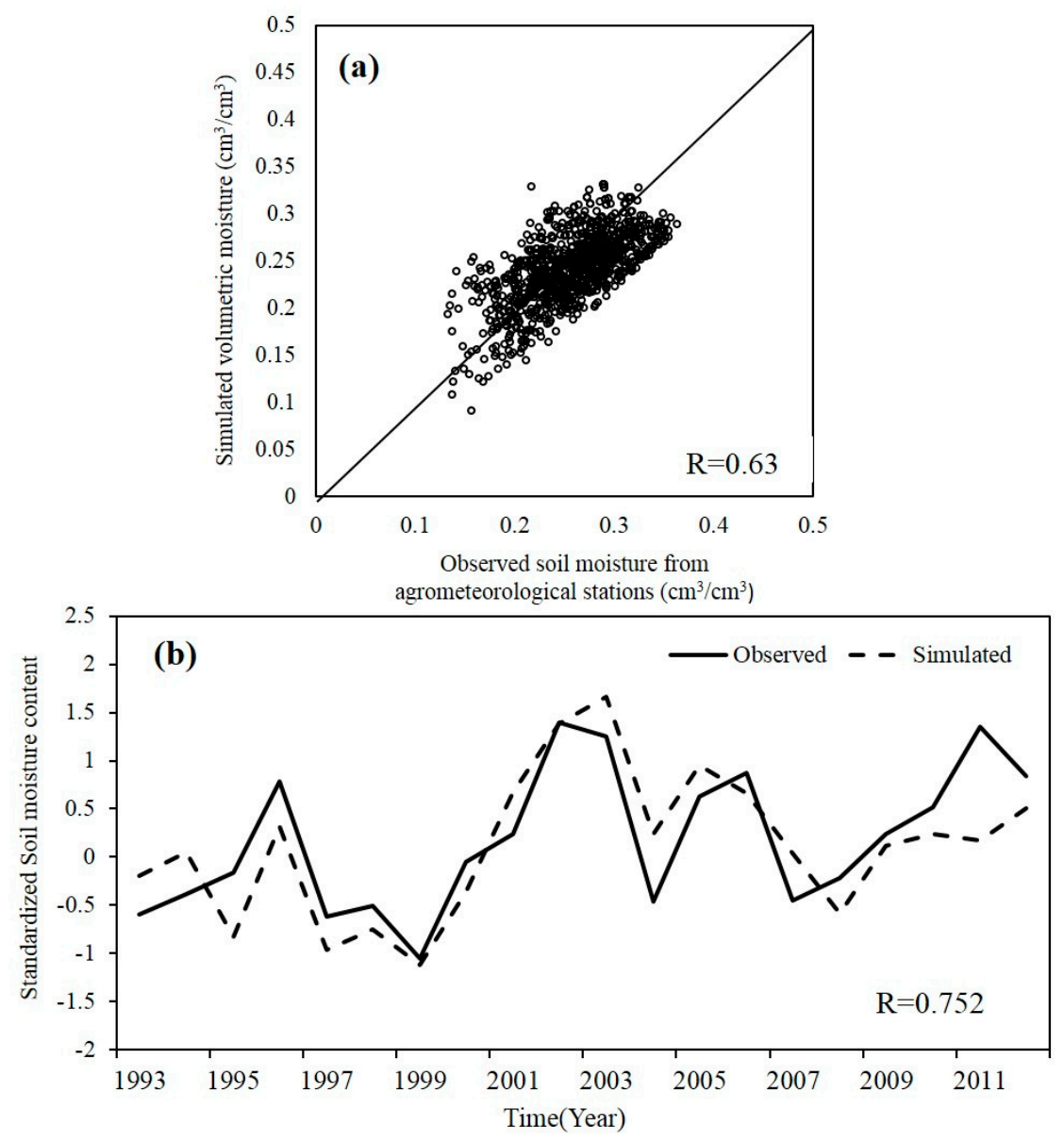

Figure 3. (a) Comparison of SWAT-simulated and observed monthly soil moisture of top 50-cm during 1993-2012; (b) interannual variations of standardized SWAT-simulated and observed average soil moisture of the WRB during 1993-2012.

\subsubsection{The Efficiency of the PDSI_SWAT in the WRB}

In our study, we construct the PDSI_SWAT drought index based on the PDSI and SWAT model. In order to test its efficiency in the description of drought conditions in the WRB, we compare it 
with several other frequently used drought indices (SPI, SSI, SPEI and PDSI). Mishra and Singh [2] suggested that shorter time scales like 3 months seem to be adequate for the identification of agricultural droughts and meteorological droughts, while longer time scales, e.g., 12 months, can better describe the hydrological and water resources droughts. Therefore, the performance of the PDSI_SWAT is first evaluated by comparing the SPI/SPEI/SSI at 12 month time scale at basin scale (noted as SPI-12, SPEI-12, SSI-12, respectively), and then, validated with the SPI/SPEI/SSI at 3 month time scale for a typical drought event. Figure 4 presents the regional average time series of SPI-12, SSI-12, SPEI-12, PDSI and PDSI_SWAT. From Figure 4, we can observe that there are little discrepancy between all these drought indices, indicating the capacity of them to describe the drought conditions in the WRB. Furthermore, Figure 5 also shows the correlations between all of these drought indices in each sub-basin of WRB, which also demonstrate the good consistency in the drought description of all drought indices. However, they also exhibit some differences in several particular periods. For example, during March to July in 1974, the WRB is expected to experience drought as quantified by PDSI_SWAT, while it is revealed to under wet conditions by the other drought indexes (SPI, SPEI and SSI). During January to April in 2003, the WRB is characterized by wet condition with PDSI_SWAT, while it shows as slight drought or moderate drought by other drought indexes (Figure 4). It is worth noting that SPI and SPEI represent the meteorological drought, which may start and end quickly, and SSI represents the agriculture drought, which may develop slowly, always persist for a long period after the meteorological drought has terminated and it may recover slowly. PDSI and PDSI_SWAT can reflect both meteorological and agriculture drought, thus the drought conditions described by this index may lie between SPI/SPEI and SSI. For example, from 1980 to 1981, the SPI and SPEI shows that the drought condition is alleviated while the PDSI_SWAT and SSI shows that the drought continues (Figure 4). Additionally, from Figure 5, we can find that PDSI_SWAT shows a higher correlation with the other drought indices than original PDSI.
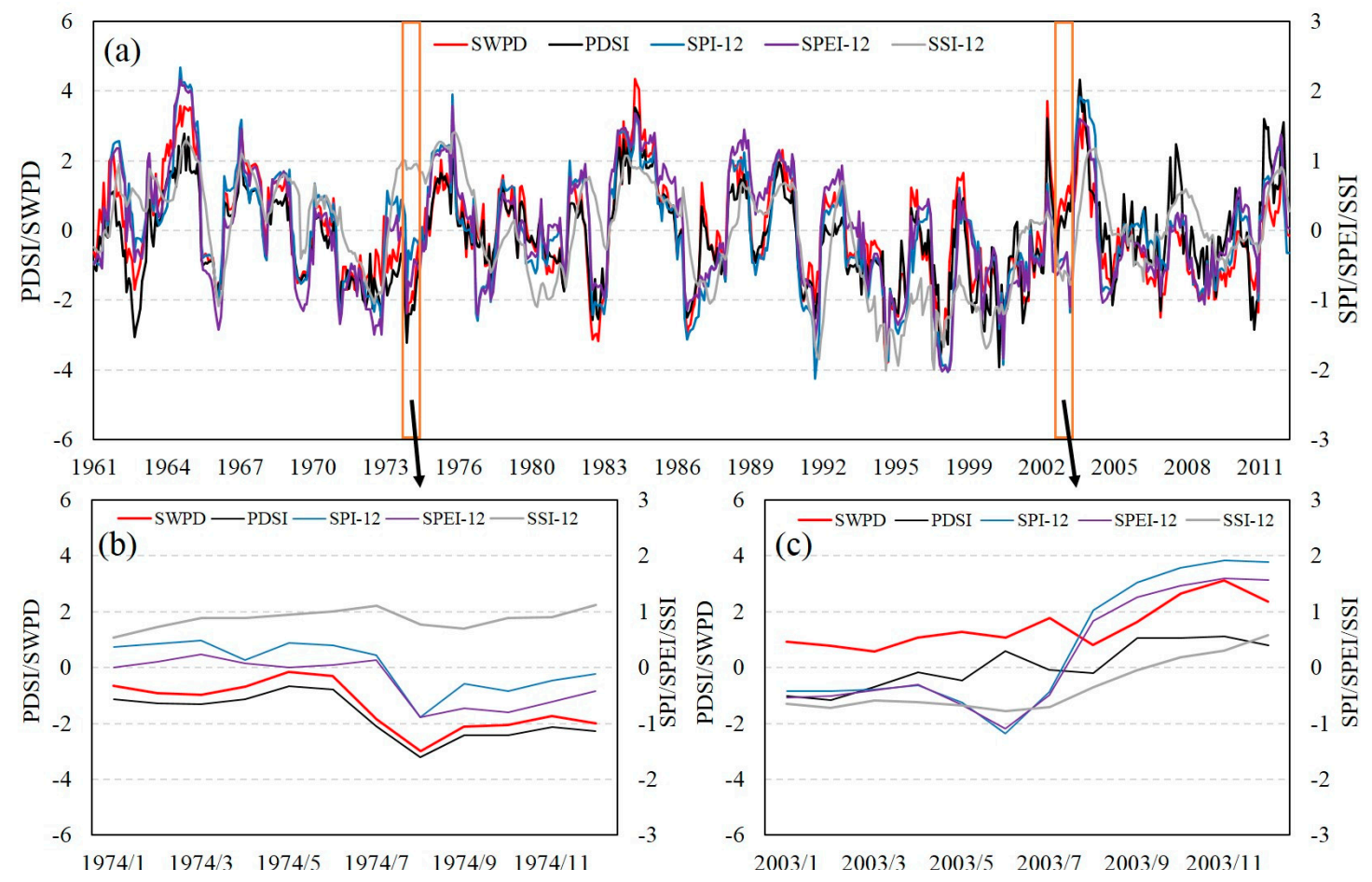

Figure 4. (a) Basin-averaged monthly PDSI/PDSI_SWAT compared with SPI-12, SPEI-12 and SSI-12 during 1961-2012; (b) Partial enlarged drawing during 1974 of Figure 4a; (c) Partial enlarged drawing during 2003 of Figure 4a. 


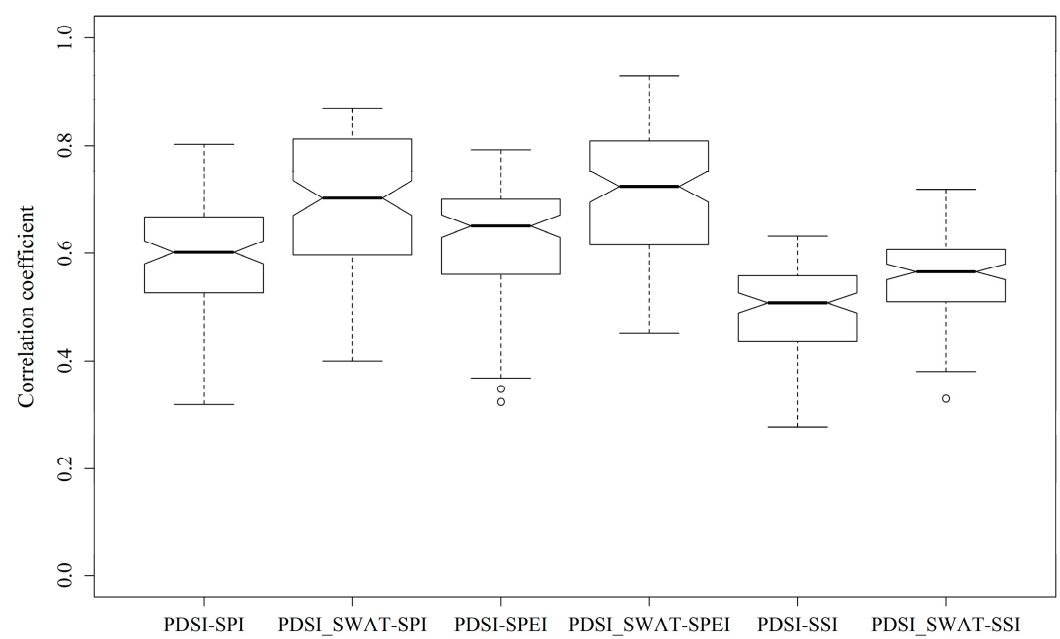

Figure 5. The boxplot of the correlation coefficient of 113 sub-basins between PDSI/PDSI_SWAT and other meteorological and agricultural drought indices during 1961-2012. The whiskers are the maximum and minimum values of the distributions, the box boundaries are the first and third quartiles, and the point within the box is the second quartile (median).

Furthermore, we also select a special drought year to test the ability of all these drought indices and find whether they can capture the drought evolution processes. The extreme drought event occurred in the WRB in 1995 [49] is chosen as a case study event in our study to evaluate the reliability and efficiency of all the drought indices (Figure 6). The drought severity in 1995 is reported to be greater than most of the historical droughts of the past in this area. Annual precipitation of 1995 $(413 \mathrm{~mm})$ in most areas of the WRB was observed to be significantly below the average level in these areas (556 mm during 1961-1995 and $547 \mathrm{~mm}$ during 1961-2012). In Shaanxi province, the area affected by this extreme drought event reached 2.01 million $\mathrm{hm}^{2}$ [50].

Here, the 3 month time scale is chosen for the SPI, SSI and SPEI for the comparison in the typical year, which are noted as SPI-3, SSI-3 and SPEI-3, respectively. It can be seen from Figure 6 that the various drought indices show similar drought patterns during 1995, which demonstrates their capacity to capture the main characteristics of this extreme drought event. However, some differences in drought severity and drought duration can also be found among these drought indices. Drought starts in the majority of the northwest WRB in March according to PDSI_SWAT, it seems to begin earlier than detected by SPI-3, SSI-3 and SPEI-3. In March, drought severity shown by SPI-3 (extreme drought) is generally more severe than the other four indices (slight drought for SSI and PDSI_SWAT; moderate drought for SPEI and original PDSI) in some sub-basins around the Jing River. From May, drought is propagated to more areas and extreme drought can be observed in most sub-basins. In July, drought is found to terminate in some sub-basins, and it is further alleviated in August. However, the drought situation in most sub-basins in the central WRB are found to be aggravated again from September and sustains to November. Finally, drought are observed to have ended in most sub-basins in the WRB in December. It is worth noting that drought severity by SSI-3 is milder than PDSI_SWAT and PDSI, while more severe than SPI-3 and SPEI-3 in some sub-basins in the central WRB during autumn (September-November).

To sum up, we can conclude that the extreme drought event in 1995 starts in March, aggravated gradually from May and finally terminated until December. The spatial distributions of the drought severity shown by the five drought indices reveal that the drought severity over northern WRB is higher than that of the remaining areas. Figure 6 also indicates that the SPI-3 is similar to the SPEI-3 but gives higher drought severity than the SPEI-3, and these two indices give shorter durations than the other drought indices. This may be because the SPI can be easily affected by short wet periods with large rainfall and the SPEI consider the evapotranspiration while the SPI only use precipitation. 
The SSI-3 gives longer drought persistence than the other drought indices. This is attributed to that the soil moisture could not ease quickly by the shorter wet period on account of the complex process and spatial connectivity in hydrology than in meteorology. Moreover, comparing the proposed PDSI_SWAT with the original PDSI, we can find that PDSI_SWAT gives lower drought severity in winter and spring while higher drought severity in summer and autumn than the original PDSI. This may due to the simple two-layer bucket model used in the original PDSI underestimate the impact of higher temperature and lower precipitation in summer and autumn, which will result in the lower PDSI values. Based on the fact that the WRB experienced drought frequently in summer and autumn, the PDSI_SWAT is more adequate for the drought monitoring and it is useful for the government to do the prevention before drought starts. Here, we will adopt the proposed PDSI_SWAT to represent and describe the drought conditions in our study area in the following sections.
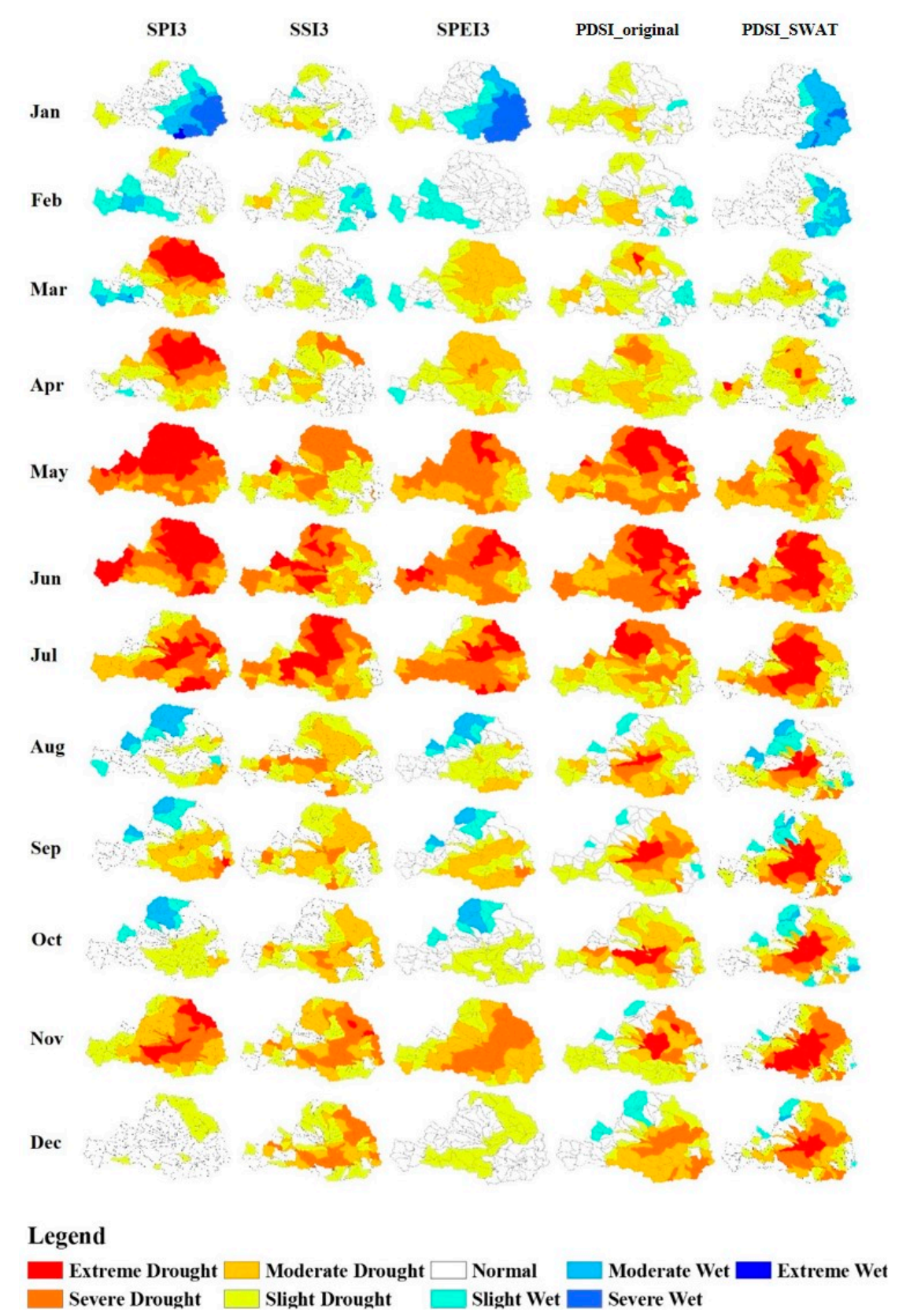

Figure 6. Spatial comparison of the drought by SPI-3, SSI-3, SPEI-3, PDSI and PDSI_SWAT in the WRB in 1995. 


\subsection{Spatiotemporal Characteristics of Drought in the WRB}

\subsubsection{Temporal Trends of Drought in the WRB}

In this study, the temporal variations of drought during 1961-2012 for each sub-basin are detected by the simple linear regression test. As presented in Figure 7, PDSI_SWAT shows a similar spatial change patterns across the 113 sub-basins of the WRB. A gradually dry trend (decreasing trends) can be observed over the WRB. Moreover, the statistic $S$ is classified into different categories under different significance levels (the critical value is $2.4,1.67$ and 1.3 for the significance level of $0.01,0.05$ and 0.1 , respectively) in order to show the spatial patterns of the significance of increasing/decreasing trend. The statistic $S$ in most sub-basins in the northern, southeastern and western WRB are lower than the rest of the basin, suggesting a more significant dry trend in these areas.

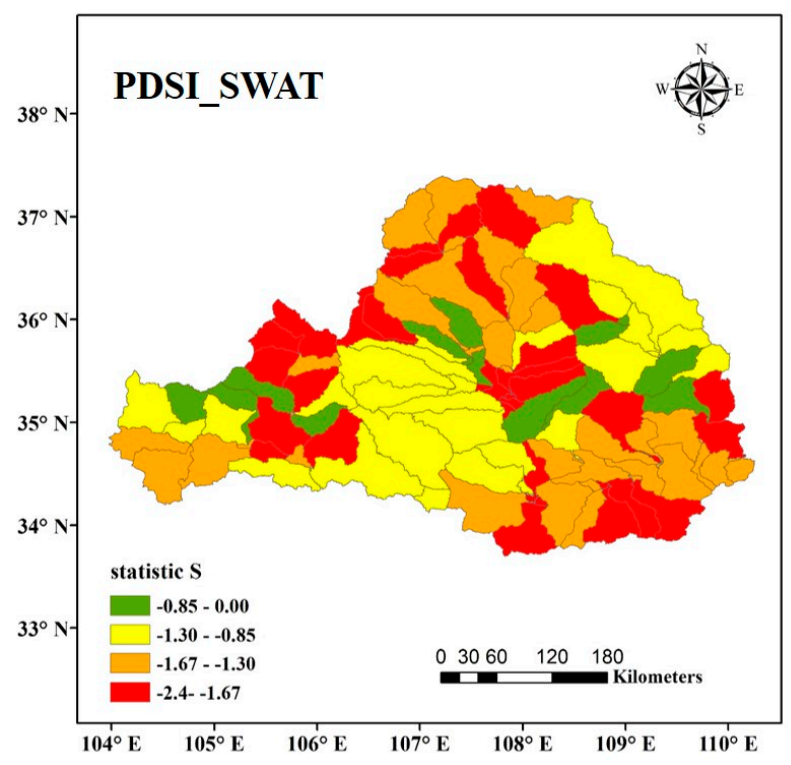

Figure 7. Spatial patterns of the statistic $S$ in the WRB (A positive/negative of the statistic $S$ indicates an increasing/decreasing trend of drought.)

Besides, we also computed the regional annual precipitation and PDSI_SWAT time series during 1961-2012 to further investigate the temporal variations of drought condition across the whole basin. Figure 8 shows that a decreasing (dry) trend can be observed during the whole period. This result is consistent with the decreasing trend of annual precipitation in Figure 8a.

\subsubsection{Spatiotemporal Characteristics of Drought Frequency}

Here, we analyze the spatial patterns of drought frequency based on the proposed PDSI_SWAT to further investigate the drought distribution in the WRB. The drought frequency is considered in the following cases: slight drought, moderate drought, severe drought, extreme drought. The sum frequency of the foregoing four types is noted as total frequency of drought. The frequency is calculated as the number of months that drought occurs divided by the total number of months. Figure 9 shows the spatial distribution of drought frequency for PDSI_SWAT during 1961-2012. For the slight drought, the areas with high frequency are mainly located in the northern and central parts of the WRB. The moderate drought frequency in most sub-basins around the upper and middle reaches of Wei River and Jing River is more than $5 \%$. The severe drought frequency mainly ranges from $1 \%$ to $3 \%$ in the southeastern of WRB and the northern parts show the highest occurrence frequency (more than $7 \%$ ). The spatial distribution of extreme drought frequency is similar to that of severe drought, with high frequency in the northern parts and low frequency in the southern parts. Finally, we can 
conclude that the drought occurs more frequently in the northern part than the southern part of the WRB. This result is consistent with the previous studies, which used a variety of drought indices to analyze the spatiotemporal characteristics of drought frequency in WRB [51,52]. The reasons can be illustrated from the perspective of the spatial distribution of annual precipitation, which decreases from southeast to the northeast of the WRB.
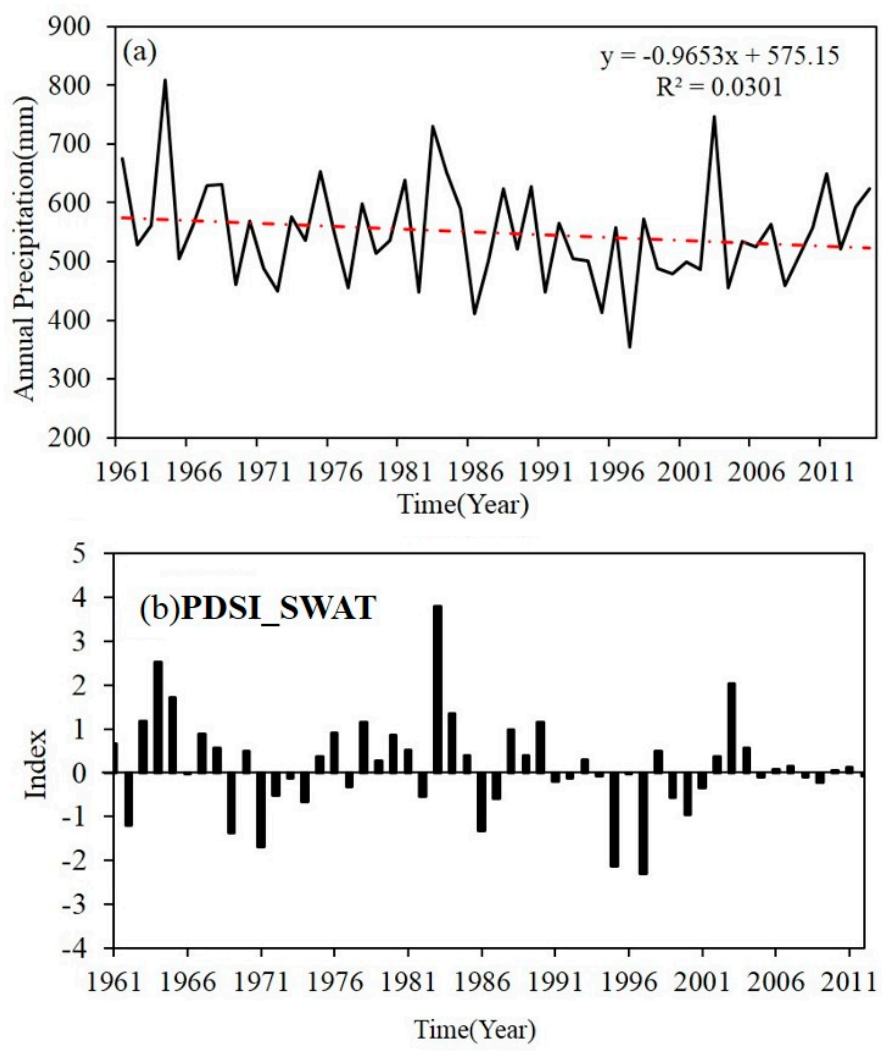

Figure 8. Interannual variation and trend of regional annual (a) precipitation and (b) PDSI_SWAT.

\subsection{PCA on PDSI_SWAT Time Series}

In this study, we further analyze drought regionalization to monitor the regional drought conditions using the PCA method. The high value of the KMO test (0.912) suggests that the proposed drought index PDSI_SWAT is adequate for the PCA method. On the other hand, the Bartlett's test of sphericity of the PDSI_SWAT has passed the test at the significance level of 0.05 , which also indicates that we can apply the PCA method to the PDSI_SWAT time series.

According to North's rule of thumb and scree plot of the eigenvalues, the first three principal components are selected for rotation in order to achieve more stable spatial patterns. The results of PCA method performed on the PDSI_SWAT is given in Table 4. The percentage of the variance explained by the first three un-rotated PCs are $60.15 \%, 10.59 \%$ and $6.60 \%$, respectively, for a cumulative variance of $77.34 \%$. High percentage indicates that most temporal drought variation of the drought index (PDSI_SWAT) across the basin can be extracted by the corresponding first three leading principal components (PCs). After the variance maximum rotation, the total variance is evenly explained by the first three leading rotated principal components (RPCs), while the cumulative variance of the RPCs remained unchanged with respect to the un-rotated cases for the PDSI_SWAT (see Table 4). 

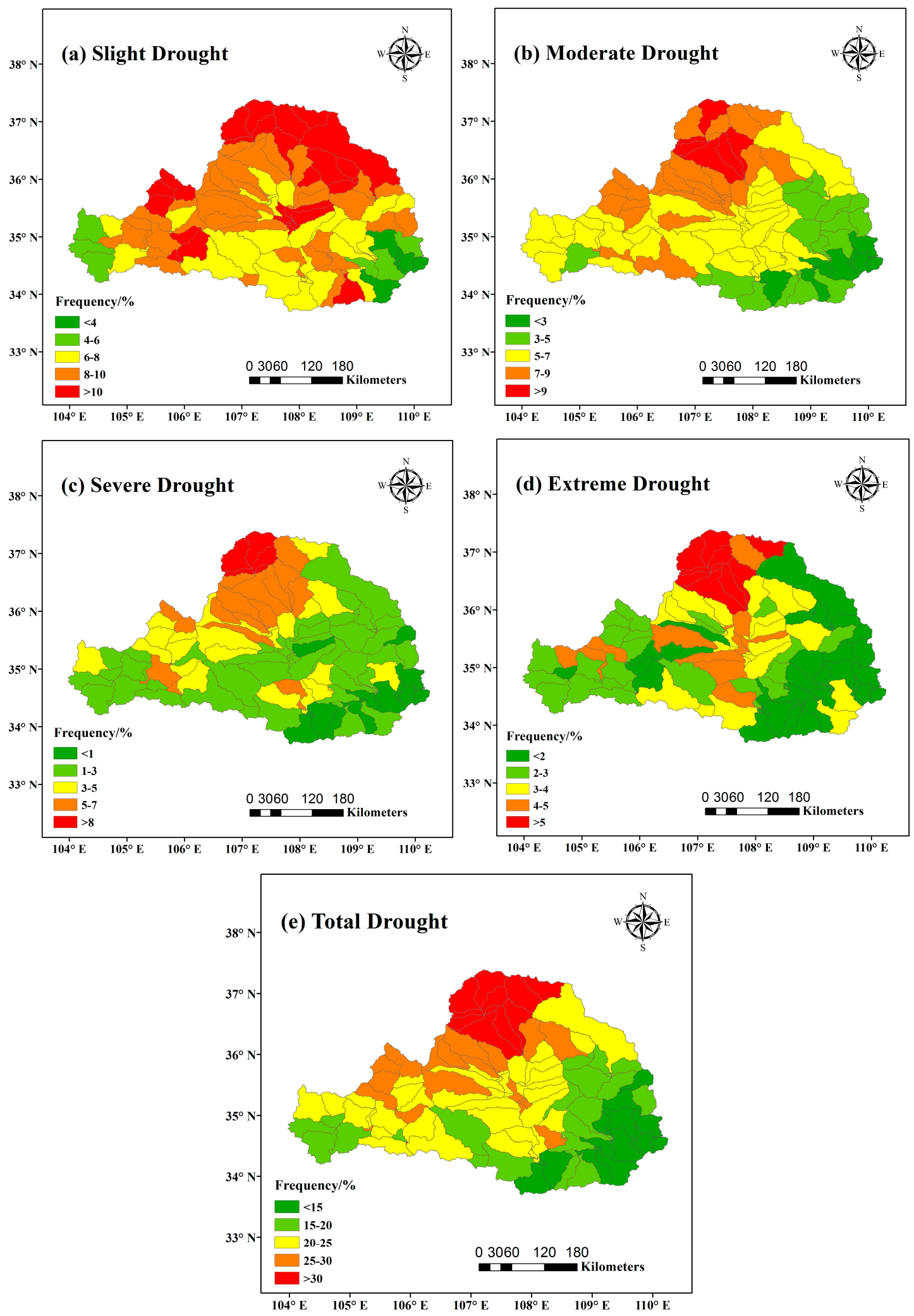

Figure 9. Spatial patterns of drought frequency of different levels of drought severity based on PDSI_SWAT: (a) Slight drought; (b) Moderate drought; (c) Severe drought; (d) Extreme drought and (e) Total drought. 
Table 4. Principal component analysis on the PDSI_SWAT for the 113 sub-basins across the whole basin.

\begin{tabular}{cccc}
\hline & \multicolumn{3}{c}{ PDSI_SWAT } \\
\cline { 2 - 4 } Principal Component & Eigenvalue & $\begin{array}{c}\text { Explained } \\
\text { Variance-Unrot (\%) }\end{array}$ & $\begin{array}{c}\text { Explained } \\
\text { Variance-Rot (\%) }\end{array}$ \\
\cline { 2 - 4 } PC1 & 67.97 & 60.15 & 34.17 \\
PC2 & 11.97 & 10.59 & 22.98 \\
PC3 & 7.46 & 6.60 & 20.20 \\
Cumulative variance & & 77.34 & 77.34 \\
\hline
\end{tabular}

The rotated loadings of the first three PCs for PDSI_SWAT are calculated for each sub-basin of the WRB. Figure 10 illustrates the spatial patterns of the rotated loadings of the PDSI_SWAT. A threshold value of $0.5-0.6$ on the loadings is reasonable for spatially delimiting the sub-regions which experience similar drought variability in the study period [53]. The loading values of the three RPC are all positive, however, the spatial distribution differs largely. The high positive loadings in the first RPC (RPC1) are located in the southeastern parts of the WRB, with the maximum loading value of 0.882 in the No. 85 sub-basin. Similarly, the high positive loadings in the RPC2 and RPC3 of PDSI_SWAT are located in northern and western parts of WRB, with the maximum loading values in No. 6 and No. 75 sub-basin, respectively. The temporal variability of the RPCs (PC score) of the PDSI_SWAT with the corresponding linear trend and the corresponding representative sub-basins are presented in Figure 11. The RPC 3 shows the largest decreasing trend, followed by RPC2 and RPC1 (Figure 11). The PC scores of the three RPCs show similar temporal patterns with the PDSI_SWAT time series in its corresponding sub-basins under all cases in Figure 11. High linear coefficients $\left(R^{2}>0.7\right)$ also suggest that the PC scores can generally capture the temporal drought variation. Moreover, the corresponding rotated PC scores of PDSI_SWAT show the multi-year fluctuations with different temporal patterns and trends, and remarkable dry events of different severity are expected to occur in different years. As given by PDSI_SWAT, the remarkable extreme drought events can be identified in 1962, 1978, 1986, 1995, 1997 and 1999 in the southeastern part of WRB by RPC1, while in 1972, 1987, 1991, 1995, 1997 and 2000 in the northern part of WRB by RPC2. As for the RPC3, it shows that the extreme drought events are occurred in 1972, 1982, 1988, 1995, 1997 and 2000 in western area of WRB. It can be seen that the three representative sub-basins are characterized by different drought variability. For example, the northern part (RPC2) was undergoing a wet period in 1962, while the southeastern part (RPC1) and the western part (RPC3) experienced drought; Moreover, while in 1978 the southeast (RPC1) experienced extreme drought, the northern (RPC2) and the western (RPC3) were characterized by near normal conditions.

Therefore, the rotated loadings of the PDSI_SWAT seem to well localize in three distinct sub-regions, i.e., the northern, southeastern and western parts of the WRB, which are characterized by different drought variability. Moreover, the representative locations with different types of drought characteristics were also identified by the PCA method. This information can help provide a further regional view of drought conditions across the WRB region with the consideration of the internal of spatial variation.

\subsection{The Correlation between ENSO Events and the PDSI_SWAT Time Series}

In our study, we use the wavelet transform analysis method to explore the changes of variance and possible linkage between RPC series and Niño 3.4 SST index series, so as to evaluate the possible impacts of ENSO on the droughts among the regions of different drought variability obtained by the PCA method. Figure 12 illustrates the cross wavelet method (XWT) and the wavelet coherence (WTC) results of the time-frequency relationships as well as their phase angles in terms of arrows (with in-phase pointing right, anti-phase pointing left), respectively. The $95 \%$ confidence intervals of the relationships are shown within the area surrounded by black thick line.

For the RPC1 loadings, which can represent the drought variability in the southeastern parts, the cross-power spectra results show a significant common power in 2- to 8-year band during 1981-1993 (Figure 12a). The sectors with significant common power dominantly present anti-phase relationships 
between the RPC1 and the Niño 3.4 SST index. From WTC, a relatively smaller region (in the 3- to 7-year band during 1982-1990) is prominent, also showing the similar results (Figure 12b). These results suggest that a higher Niño 3.4 index usually corresponds to a lower RPC1 value (more severe drought) over this region.
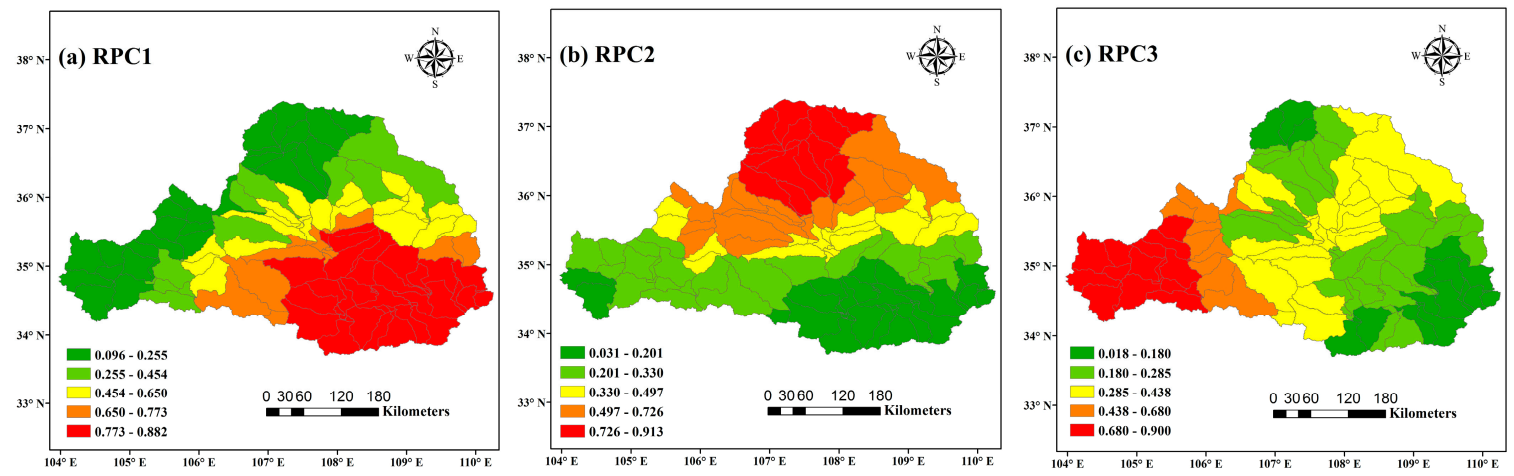

Figure 10. Spatial patterns of the rotated loadings of the first three principal components based on principal component analysis on the PDSI_SWAT time series: (a) RPC1, (b) RPC2 and (c) RPC3.
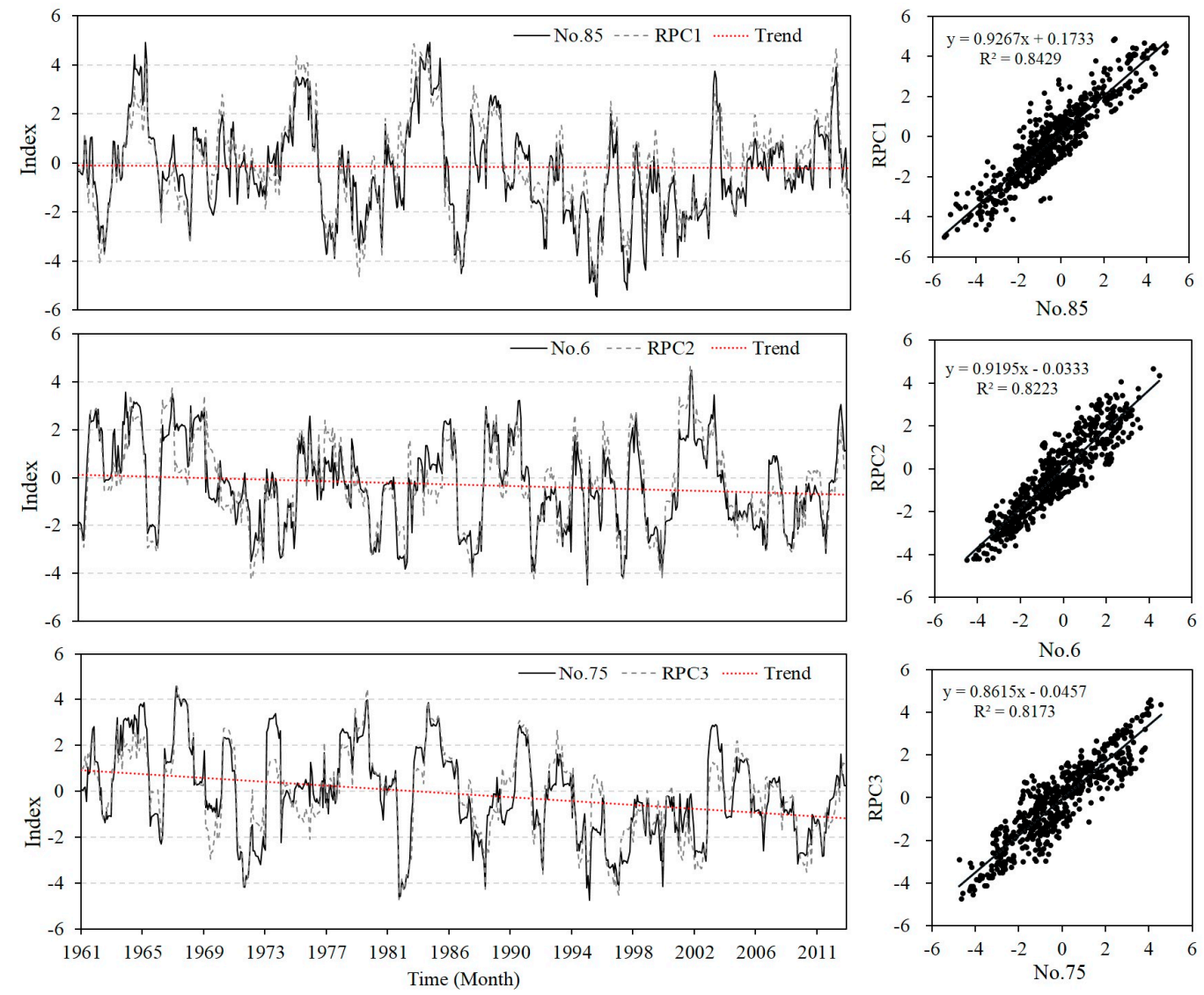

Figure 11. Temporal patterns of drought severity based on PDSI_SWAT for the rotated principal component (PC) scores and the corresponding representative sub-basins (No. 85, No. 6 and No. 75).

With regard to RPC2, significant and relatively high common wavelet power exists in the 3- to 6-year band during 1985-1992, the 3- to 7-year band during 1995-2003 and the 12-14 year band during 1978-2005 (Figure 12c). The phase changes in these regions that are significant at 95\% confidence level, showing in-phase and antiphase in different study periods. The WTC of RPC2 demonstrates a small 
region (in 2- to 4-year band during 1982-1989) with higher coherency peaks (Figure 12d). The phase in the region show clear anti-phase relationships between RPC2 and Niño 3.4 SST.

The XWT of RPC3 show common features with significant wavelet power spectra at 95\% confidence level, and these power spectra occurred in the 2- to 4-year band during 1965-1971 and the 4- to 6-year band during 1975-1990 (Figure 12e). These regions show clear anti-phase between the RPC3 series and Niño 3.4 SST. The WTC of RPC3 demonstrates that regions (in the 2- to 4-year band in 1965-1978) with anti-phase angles (Figure 12f). Also, significant wavelet power sectors with in-phase angles are noticed in the 11- to 16-year band during 1975-1998.

The wavelet analysis detected the correlations between RPC and Niño 3.4 SST index in the three distinct regions. These statistically significant positive or negative correlations directly indicate that the ENSO events have strong impacts on inducing droughts in the WRB.
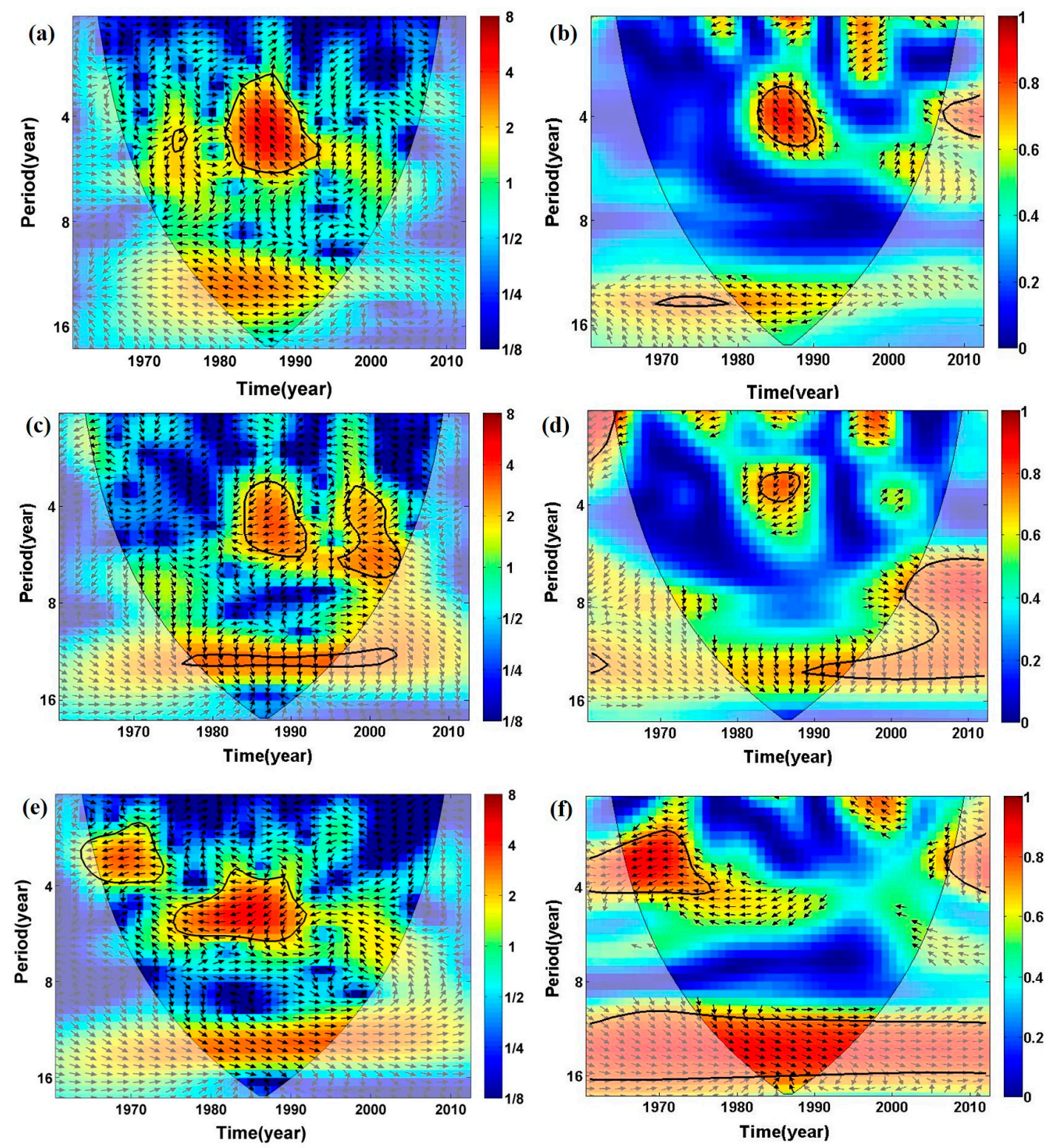

Figure 12. Cross wavelet method (XWT) and wavelet coherence (WTC) for the three principal components (a) rotated principal component (RPC)1-XWT; (b) RPC1-WTC; (c) RPC2-XWT; (d) RPC2-WTC; (e) RPC3-XWT; (f) RPC3-WTC. 


\section{Conclusions}

In this study, the spatiotemporal variations of drought characteristics are analyzed in the Wei River Basin (WRB) during 1961-2012. To improve the efficiency of PDSI_original, we replace the two-layer model in the hydrologic accounting section of PDSI with the SWAT model, and construct the PDSI_SWAT drought index. The effectiveness of PDSI_SWAT is tested with the other four commonly used drought indices. Furthermore, the principal component analysis is used to monitor the regional drought conditions based on constructed drought index PDSI_SWAT in the WRB, and the changes of drought frequency are performed. Finally, we also intend to find out the potential caused for the drought variations in the study area. The major conclusions of this study can be drawn as follows:

(1) The SWAT model can provide good simulation of the hydrological and meteorological variable, which can be used in the computation of all drought indices. The comparison among the SPI, SSI, SPEI, PDSI and PDSI_SWAT shows that all these indices can well capture the drought events in the WRB, although there exists some discrepancy in the description of drought propagation processes. In particular, the constructed PDSI_SWAT performs well in presenting the spatiotemporal variation of drought characteristics across the WRB, as it can not only consider the precipitation but also can reflect a relatively stable variation of moisture condition.

(2) The whole WRB is undergoing a dry trend, with the trends in the northern, southeastern and western WRB being more significant than the remaining regions. The drought frequencies reveal that drought seems to be more likely to occur in the northern part than the southern part of WRB. The high drought frequencies of slight, moderate, severe and extreme drought are all observed in the northwestern WRB. Therefore, the drought risk in the northern WRB probably increased during the past several decades.

(3) The principle component analysis method based on the PDSI_SWAT at all 113 sub-basins reveals that the three leading PCs can well reflect the drought variability in the WRB. Moreover, the whole basin can be further divided into three distinct sub-regions with different drought variability, i.e., the northern, southeastern and western part. Additionally, these three sub-regions are also consistent with the spatial pattern of drought shown by the drought frequency. The wavelet transform analysis method indicates that the ENSO events have strong impacts on inducing droughts in the WRB.

The results of this study could be helpful for the efficient water resources management and drought analysis. The findings of this study could also serve as a valuable reference for future drought research in the WRB.

Acknowledgments: This study was supported by the National Natural Science Foundation of China (41571028 and 41501030). We are very grateful to the editor and four anonymous reviewers for their valuable comments and constructive suggestions that helped us to greatly improve the manuscript.

Author Contributions: This research presented here was carried out in collaboration between all authors. Lei Zou processed the data and carried out the statistical analysis of results; Jun Xia and Dunxian She provided many significant suggestions on the methodology and structure of the manuscript.

Conflicts of Interest: The authors declare no conflict of interest.

\section{References}

1. Wilhite, D.A. Drought: A Global Assessment; Routledge: New York, NY, USA, 2000.

2. Mishra, A.K.; Singh, V.P. A review of drought concepts. J. Hydrol. 2010, 391, 202-216. [CrossRef]

3. Keshavarz, M.R.; Vazifedoust, M.; Alizadeh, A. Drought monitoring using a Soil Wetness Deficit Index (SWDI) derived from MODIS satellite data. Agric. Water Manag. 2014, 132, 37-45. [CrossRef]

4. Wilhite, D.A. Drought Assessment, Management and Planning: Theory and Case Studies; Kluwer Academic Publishers: New York, NY, USA, 1993; p. 293.

5. Dubrovsky, M.; Svoboda, M.D.; Trnka, M.; Hayes, M.J.; Wilhite, D.A.; Zalud, Z.; Hlavinka, P. Application of relative drought indices in assessing climate-change impacts on drought conditions in Czechia. Theor. Appl. Climatol. 2009, 96, 155-171. [CrossRef]

6. Paneque, P. Drought Management Strategies in Spain. Water 2015, 7, 6689-6701. [CrossRef] 
7. Heim, R.R. A review of twentieth-century drought indices used in the United States. Bull. Am. Meteorol. Soc. 2002, 83, 1149-1165.

8. Hao, Z.; Singh, V.P. Drought characterization from a multivariate perspective: A review. J. Hydrol. 2015, 527, 668-678. [CrossRef]

9. Hao, Z.; AghaKouchak, A. A nonparametric multivariate multi-index drought monitoring framework. J. Hydrometeorol. 2014, 15, 89-101. [CrossRef]

10. Wilhite, D.A.; Glantz, M.H. Understanding the Drought Phenomenon: The Role of Definitions. Water Int. 1985, 10, 111-120. [CrossRef]

11. Palmer, W.C. Meteorological Drought; Technical Report No. 45; U.S. Department of Commerce Weather Bureau Research: Washington, DC, USA, 1965.

12. Dai, A. Characteristics and trends in various forms of the palmer drought severity index during 1900-2008. J. Geophys. Res.-Atmos. 2011, 116. [CrossRef]

13. Wells, N.; Goddard, S.; Hayes, M.J. A self-calibrating palmer drought severity index. J. Clim. 2004, 17, 2335-2351. [CrossRef]

14. Mavromatis, T. Drought index evaluation for assessing future wheat production in Greece. Int. J. Climatol. 2007, 27, 911-924. [CrossRef]

15. Yan, D.H.; Shi, X.L.; Yang, Z.Y.; Li, Y.; Zhao, K.; Yuan, Y. Modified palmer drought severity index based on distributed hydrological simulation. Math. Probl. Eng. 2013, 2013, 327374. [CrossRef]

16. Ma, M.; Ren, L.; Singh, V.P.; Yuan, F.; Chen, L.; Yang, X.; Liu, Y. Hydrologic model-based palmer indices for drought characterization in the Yellow River Basin, China. Stoch. Environ. Res. Risk Assess. 2015, 30, 1401-1420. [CrossRef]

17. Zrinji, Z.; Burn, D.H. Flood frequency-analysis for ungauged sites using a region of influence approach. J. Hydrol. 1994, 153, 1-21. [CrossRef]

18. Rajsekhar, D.; Mishra, A.K.; Singh, V.P. Regionalization of drought characteristics using an entropy approach. J. Hydrol. Eng. 2012, 18, 870-887. [CrossRef]

19. Choquette, A.F. Regionalization of Peak Discharges for Streams in Kentucky; Water Resources Investigation Report 87-4209; U.S. Geological Survey: Louisville, KY, USA, 1998.

20. Rencher, A.C. Multivariate Statistical Inference and Applications; Wiley: Hoboken, NJ, USA, 1998; p. 559.

21. Martins, D.S.; Raziei, T.; Paulo, A.A.; Pereira, L.S. Spatial and temporal variability of precipitation and drought in Portugal. Nat. Hazards Earth Syst. Sci. 2012, 12, 1493-1501. [CrossRef]

22. Gocic, M.; Trajkovic, S. Spatiotemporal characteristics of drought in Serbia. J. Hydrol. 2014, 510, 110-123. [CrossRef]

23. Liu, Z.P.; Wang, Y.Q.; Shao, M.G.; Jia, X.X.; Li, X.L. Spatiotemporal analysis of multiscalar drought characteristics across the loess plateau of China. J. Hydrol. 2016, 534, 281-299. [CrossRef]

24. Lei, J.Q.; Huang, Q.; Wang, Y.M. Variable fuzzy evaluation on comprehensive divisions of drought in the Wei River basin. J. Hydraul. Eng. 2014, 45, 574-584. (In Chinese)

25. McKee, T.B.; Doesken, N.J.; Kleist, J. The relationship of drought frequency and duration to time scales. In Proceedings of the 8th conference on applied climatology, Anaheim, CA, USA, 17-22 January 1993.

26. Hao, Z.; AghaKouchak, A. Multivariate Standardized Drought Index: A parametric multi-index model. Adv. Water Resour. 2013, 57, 12-18. [CrossRef]

27. Vicente-Serrano, S.M.; Beguería, S.; López-Moreno, J.I. A multi-scalar drought index sensitive to global warming: The standardized precipitation evapotranspiration index-SPEI. J. Clim. 2010, 23, 1696-1718. [CrossRef]

28. Weng, H.; Lau, K.; Xue, Y. Multi-Scale summer rainfall variability over China and its long-term link to global sea surface temperature variability. J. Meteorol. Soc. Jpn. 1999, 77, 845-857.

29. Feng, J.; Chen, W.; Tam, C.Y.; Zhou, W. Different impacts of EI Niño and EI Niño Modoki on China rainfall in the decaying phases. Int. J. Climatol. 2011, 31, 2091-2101. [CrossRef]

30. Liu, Z.Y.; Menzel, L.; Dong, C.Y.; Fang, R.H. Temporal dynamics and spatial patterns of drought and the relation to ENSO: A case study in northwest China. Int. J. Climatol. 2016, 36, 2886-2898. [CrossRef]

31. Chang, J.X.; Wang, Y.M.; Istanbulluoglu, E.; Bai, T.; Huang, Q.; Yang, D.W.; Huang, S.Z. Impact of climate change and human activities on runoff in the Weihe River Basin, China. Quatern. Int. 2015, 380, 169-179. [CrossRef] 
32. Guo, R.; Zha, X.C. Analysis on the change law of drought and flood disaster in Jinghe basin from 1470 to 1979. J. Shaanxi Norm. Univ. 2009, 37, 90-95. (In Chinese)

33. China Meteorological Administration (CMA). Agrometeorological Observation Specification-Soil Volume; China Meteorological Press: Beijing, China, 1993. (In Chinese)

34. Guttman, N.B. Comparing the Palmer drought index and the standardized precipitation index. JAWRA J. Am. Water Resour. Assoc. 1998, 34, 113-121. [CrossRef]

35. Gassman, P.W.; Reyes, M.R.; Green, C.H.; Arnold, J.G. The soil and water assessment tool: Historical development, applications, and future research directions. Trans. Am. Soc. Agric. Biol. Eng. 2007, 50, 1211-1250. [CrossRef]

36. Ligaray, M.; Kim, H.; Sthiannopkao, S.; Lee, S.; Cho, K.H.; Kim, J.H. Assessment on hydrologic response by climate change in the Chao Phraya River Basin, Thailand. Water 2015, 7, 6892-6909. [CrossRef]

37. Abbaspour, K.C. User Manual for SWAT-CUP, SWAT Calibration and Uncertainty Analysis Programs; Swiss Federal Institute of Aquatic Science and Technology (Eawag): Dübendorf, Switzerland, 2007.

38. World Climate Program-Water, World Climate Data and Monitoring Programme (WCDMP)-45. Detecting Trend and Other Changes in Hydrological Data; Kundzewicz, Z.W., Robson, A., Eds.; World Meteorological Organization: Geneva, Switzerland, 2000.

39. Huang, J.; Ho, M.; Du, P. Assessment of temporal and spatial variation of coastal water quality and source identification along Macau Peninsula. Stoch. Environ. Res. Risk Assess. 2011, 25, 353-361. [CrossRef]

40. Kim, J.Y.; An, K.G. Integrated ecological river health assessments, based on water chemistry, physical habitat quality and biological integrity. Water 2015, 7, 6378-6403. [CrossRef]

41. Richman, M.B. Rotation of principal components. Int. J. Climatol. 1986, 6, 293-335.

42. Von Storch, H.; Zwiers, F.W. Statistical Analysis in Climate Research; Cambridge University Press: Cambridge, UK, 1999; p. 484.

43. North, G.R.; Bell, T.L.; Cahalan, R.F.; Moeng, F.J. Sampling errors in the estimation of empirical orthogonal functions. Mon. Weather Rev. 1982, 110, 699-706. [CrossRef]

44. Kaiser, H.F. A second generation little jiffy. Psychometrika 1970, 35, 401-415. [CrossRef]

45. Bartlett, M.S. A Note on the Multiplying Factors for Various $\chi 2$ Approximations. J. R. Stat. Soc. Ser. B (Methodol.) 1954, 16, 296-298.

46. Grinsted, A.; Moore, J.C.; Jevrejeva, S. Application of the cross wavelet transform and wavelet coherence to geophysical time series. Nonlinear Proc. Geoph. 2004, 11, 561-566. [CrossRef]

47. Torrence, C.; Compo, G.P. A practical guide to wavelet analysis. Bull. Am. Meteorol. Soc. 1998, 79, 61-78. [CrossRef]

48. Yu, H.L.; Lin, Y.C. Analysis of space-time non-stationary patterns of rainfall-groundwater interactions by integrating empirical orthogonal function and cross wavelet transform methods. J. Hydrol. 2015, 525, 585-597. [CrossRef]

49. Yang, X.; Li, S.G. The heaviest drought in Shaanxi Province in 1995. J. Catastr. 1997, 12, 77-79. (In Chinese)

50. Yang, X. Analysis of drought characteristics in Shaanxi Province. J. Shaanxi Meteorol. 1998, 4, $22-25$. (In Chinese)

51. Huang, S.Z.; Huang, Q.; Chang, J.X.; Leng, G.Y.; Xing, L. The response of agricultural drought to meteorological drought and the influencing factors: A case study in the Wei River Basin, China. Agric. Water Manag. 2015, 159, 45-54. [CrossRef]

52. Chang, J.X.; Li, Y.Y.; Wang, Y.M.; Yuan, M. Copula-based drought risk assessment combined with an integrated index in the Wei River Basin, China. J. Hydrol. 2016, 540, 824-834. [CrossRef]

53. Huang, J.; Xue, Y.; Sun, S.L.; Zhang, J.C. Spatial and temporal variability of drought during 1960-2012 in Inner Mongolia, North China. Quatern. Int. 2015, 355, 134-144. [CrossRef]

(C) 2017 by the authors. Licensee MDPI, Basel, Switzerland. This article is an open access article distributed under the terms and conditions of the Creative Commons Attribution (CC BY) license (http:/ / creativecommons.org/licenses/by/4.0/). 